\title{
Prevalence of Subclinical Left Ventricular Diastolic Dysfunction in Patient with Metabolic Syndrome in West Region of the Republic of acedonia
}

\author{
Ylber Jani ${ }^{1 *}$, Atila Rexhepi ${ }^{2}$, Bekim Pocesta ${ }^{3}$, Sotiraq Xhunga ${ }^{4}$, Artur Serani ${ }^{4}$, Fatmir Ferati ${ }^{4}$, Dali Lala ${ }^{5}$, Agim \\ Zeqiri $^{6}$, Arben Mirto ${ }^{7}$ and Ahmet Kamberi ${ }^{8}$
}

${ }^{1}$ Private Health Institute "Heart Diagnostica", Republic of Macedonia

${ }^{2}$ Department of Internal Medicine, Faculty of Medicine, Republic of Macedonia

${ }^{3}$ Department of Cardiology, Faculty of Medicine "Ss Kiril and Metodij", University Skopje, Republic of Macedonia

${ }^{4}$ Department of Cardiology, Medical Center, Republic of Albania

${ }^{5}$ Private Health Institute of Family Medicine "Florenc", Republic of Macedonia

${ }^{6}$ Department of Internal Medicine-General Hospital “DR Ferit Murat", Republic of Macedonia

${ }^{7}$ Private Health Institute "Rostusha", Republic of Macedonia

${ }^{8}$ Department of Cardiology, Faculty of Medicine, Republic of Albania

Submission: April 18, 2018; Published: July 13, 2018

*Corresponding author: Ylber Jani, Private Health Institute “Heart Diagnostica” Debar Republic of Macedonia, Email: ylber_jani@hotmail.com

Abstract

Background: Metabolic Syndrome (MetS) has been associated with subclinical changes in cardiac structure and function, including left ventricular diastolic dysfunction (LVDD) and is strong risk factors for the future development of clinical heart failure and specifically increases the risk of heart failure with preserved ejection fraction. To date, the evidence on the prevalence of subclinical LVDD in patient with MetS and relation to components of the MetS, in west region of the Republic of Macedonia are scarce.

Objective: We sought to determine the prevalence of subclinical LVDD and relation to components of the MetS, in patient with MetS in our region.

Methods: We conducted a multicenter observational cross-sectional study. Recruited were 550 consecutive participants, 450 with MetS (mean age 50 years, $49 \%$ women) and 100 controls (no risk factors for MetS; mean 51 years, $57 \%$ women), who attended outpatient visits at general cardiology Health Care Clinics in 6 town on western region Republic of Macedonia, during 1 calendar year. Participants under echocardiography with tissue Doppler imaging.

Results: Participants with MetS, have significantly increased frequency of subclical LVDD grade 1, in comparation with participants without MetS (39,7\% vs. $6 \%, p=0.0005)$. The overall frequency of subclinical LVDD grade 1 , in participants with MetS, was $39,7 \%$; $p=0.0005)$. Subjects with MetS also had worse measures of diastolic function, including: higher Lev Atrial Volume index $\{(\mathrm{LAVI}),(\mathrm{p}=0.00)$, lower $\mathrm{E} / \mathrm{A}$ ratio $(\mathrm{p}=0.00)$, lower mean $\mathrm{e}^{\prime}(\mathrm{p}=0.00)$ and lower $\mathrm{E} / \mathrm{e}^{\prime}$ ratio $(\mathrm{p}=0.00)$, increased Deceleration time $\{(\mathrm{DT}),(\mathrm{p}=0.00)\}$ and Isovolumetric Relaxation time $\{($ IVRT $)$, $(p=0.00)$. Overall, participants with subclinical LVDD, had a worse cardiovascular risk factor profile, including: higher BMI $(p=0.001)$, higher blood pressure $\{(B P)(p=0.003)\}$, elevated Weist circumference $\{(W C)(p=0.001)\}$ and dyslipidemia $(p=0.000)$ in comparation with participants with normal diastolic function. Also, participants with subclinical LVDD, have more risk factors for MetS than participants with normal diastolic function ( $\mathrm{p}=0.002)$. There was a significant association between subclinical LVDD and: Age (OR=1.108; 95\%CI1.051-1.168), Females $(\mathrm{OR}=3.633 ; 95 \% \mathrm{CI} 2.439-5.413)$, BMI (OR=7.474; 95\%CI4.881-11.443), control of BP(OR=1.763;95\% CI 1.204-2.580) and number of MetS risk factors (OR=3.609; 95\%CI 2.054-6.340).

Conclusion: The prevalence of subclinical LVDD in the patients with MetS, in absence of coronary disease and other well know heart disease, is considerably high in western region of the Republic of Macedonia and seem to be significantly associated with age, gender, BMI, Left Ventricular mass index (LVMI) and number of risk factors for MetS.

Keywords: Metabolic syndrome; Prevalence; Western region of the Republic of Macedonia

Abbrevations: MetS: Metabolic Syndrome; BW: Body Weight; BH: Body Height; BMI: Body Mass Index; BP: Blood Pressure; SBP: Systolic Blood Pressure; DBP: Diastolic Blood Pressure; DM: Diabetes Mellitus; WC: Waist Circumference; CVD: Cardio-Vascular Disease; CHD: Coronary Heart Disease; LV: Left Ventricular; LVDF: Left Ventricular Diastolic Function; LVDD: Left Ventricular Diastolic Dysfunction; HF: Heart Failure; HF-nEF: Heart Failure with Normal Ejection Fraction; CVHD: Cardio-vascular Heart Disease; DF: Diastolic Function; DD: Diastolic Dysfunction; HDL-C: serum High Density Lipoproteins Cholesterol; TG: Serum Triglycerides; TDI: Tissue Doppler Imaging; LVEF: LV Ejection Fraction; LAVI: Left Atrial Volume Index; IVRT: Isovolumetric Relaxation Time; DCT: Deceleration Time; ASE: American Society of Echocardiography 


\section{Introduction}

Since Reaven [1] established the clinical importance of the clustering of the metabolic disorders dysglicemia, central adiposity, hypertension and dyslipidemia (low levels of high density lipoprotein cholesterol (HDL-C) and high levels of triglycerides), known as the metabolic syndrome (MetS), many studies[2,3], have shown a high risk of cardiovascular disease(CVD) in the presence of MetS. Metabolic Syndrome (MetS) has been associated with subclinical changes in cardiac structure and function, including left ventricular diastolic dysfunction [4] (LVDD). Previous studies have shown that subclinical LVDD, is strong risk factors for the future development of clinical heart failure (HF), and specifically increase the risk of heart failure with preserved ejection fraction [5,6] (HFpEF). The pathways leading to subclinical LVDD are diverse, and mechanisms of progression to heart failure poorly understood. In the MetS, Left ventricular diastolic function (LVDF) appear to worsen in a stepwise fashion with the number of risk factors for MetS [4,7]. These findings may account in part for the augmented cardiovascular morbidity and mortality that is associated with MetS [8]. The dramatically increasing prevalence of the MetS, associated with the substantial increase in obesity and diabetes, is therefore, an important public health concern [9]. The true prevalence of subclinical LVDD in MetS and relation to components of the MetS are not well defined. To date, the evidence on the prevalence of subclinical LVDD and relation to components of the MetS, in patient with MetS in west region of the Republic of Macedonia are scarce. It would therefore be worthwhile to investigate the prevalence of subclinical LVDD in patient with MetS in our region.

\section{Objective}

We sought to determine the prevalence of subclinical LVDD and relation to components of the MetS, in patient with MetS, in our region.

\section{Methods}

\section{Study design}

We conducted a multicenter observational cross-sectional study. Recruited were 550 consecutive participants, 450 with MetS and 100 controls without MetS, who attended outpatient visits at general cardiology Health Care Clinics in 6 town on western region Republic of Macedonia, during 1 calendar year (from November 2016 to November 2017). The study is in compliance with the Declaration of Helsinki. All patient that participated in this study were written informed, consent was obtained from all participating patients before they were enrolled into the study.

MetS was defined according to the harmonized definition of the International Diabetes Federation and other organizations [10], that three or more out of five following criteria are considered as MetS: (1) central adiposity \{Waist circumference (WC) $\}>102 \mathrm{~cm}$ in men and $>88 \mathrm{~cm}$ in women); (2) serum HDL-C $<50 \mathrm{mg} / \mathrm{dL}$ in women or $<40 \mathrm{mg} / \mathrm{dL}$ in men; (3) serum triglyceride levels $>150 \mathrm{mg} / \mathrm{dL}$; (4) $\mathrm{SBP} \geq 130 \mathrm{~mm} \mathrm{Hg}$ or $\mathrm{DBP} \geq 85 \mathrm{mmHg}$ or use of antihypertensive drugs; (5) the presence of diabetes mellitus(DM) or use of anti-diabetic drugs. Controls without MetS were defined as meeting none of the 5 criteria for MetS. Participants with existing cardiovascular disease (heart failure, LV ejection fraction (LVEF) $<50 \%$, coronary artery disease, congenital or acquired valvular heart disease, cardiomyopathies, cardiac wall hypertrophy, cardiac arrhythmias), patient with history of stroke, were excluded from the study.

All participants underwent a comprehensive medical history and physical examination. Resting heart rate, anthropometrics, blood pressure (obtained after $10 \mathrm{~min}$ of rest in the sitting position, expressed as the average of 3 consecutive measurements). Hypertension was defined as a systolic blood pressure $\geq 140 \mathrm{mmHg}$, diastolic blood pressure $\geq 90 \mathrm{mmHg}$ and/or current anti-hypertensive therapy [11]. Diabetes mellitus was defined as a fasting serum glucose level $\geq 126 \mathrm{mg} / \mathrm{dL}$ and/or current medical therapy with an oral hypoglycemic agent and/or insulin [12]. Body mass index (BMI) was calculated as weight $(\mathrm{kg})$ divided by the square of the height $\left(\mathrm{m}^{2}\right)$. Weight was measured with weight balance scales and height with stadiometer. WC was reported in $\mathrm{cm}$. An overnight fasting blood sample was drawn from each patient to determine: blood glucose, lipid profile tests total serum cholesterol (TC), serum High density lipoproteins cholesterol (HDL-C), serum triglycerides (TG). The sample analysis was performed using standard biochemical analytical methods.

\section{Echocardiographic measurements}

M-mode, two-dimensional and Doppler echocardiography, were performed and/or reviewed by experienced staff cardiologists, compliant with the recommendation of the American Society of Echocardiography [13] (ASE), stored in DICOM format and later reviewed by two experienced echocardiographers. Briefly, the LV (left ventricular) linear dimensions were measured from a parasternal long-axis view according the recommendations of the ASE [13]. The LV mass was calculated with a validated formula and indexed for body surface area (BSA) [14]. The LV relative wall thickness was calculated as follows: (2xposterior wall thickness) divided by end-diastolic diameter [15]. The LV ejection fraction (EF), was calculated by biplane modified Simpson's rules. From an apical 4-chamber view, transmittal flow was sampled by pulsed-wave Doppler at the level of mitral valve leaflet tips. Peak velocities of the early phase (E) and late phase (A), of the mitral inflow were measured and their ratio (E/A) was calculated. Left ventricular myocardial velocities were evaluated by tissue Doppler imaging (TDI). Pulse TDI sample volume was placed at the level of the lateral and septal mitral valve annulus and peak early diastolic velocities ( $\left.\mathrm{e}^{\prime}\right)$ were measured and then averaged. The ration between $\mathrm{E}$ and e' (E/ e') was calculated.

\section{Diastolic function}

We used measurements of LA size, tissue Doppler and Doppler of mitral flow as parameters of diastolic dysfunction (DD) and the cut-offs were set according to previously published data and international guidelines [16-18]. We defined LA size as normal 
$\left(<2.2 \mathrm{~cm} / \mathrm{m}^{2}\right)$, moderately enlarged $\left(2.2-2.79 \mathrm{~cm} / \mathrm{m}^{2}\right)$ and severely enlarged $\left(\geq 2.8 \mathrm{~cm} / \mathrm{m}^{2}\right)$. E/A ratio, the ratio of the E-wave and peak late $\mathrm{LV}$ filling (A-wave), were divided into low $(<1.0)$, normal (1.0$2.0)$ and high $(>2.0)$. The early myocardial peak velocity of the mitral annulus, tissue Doppler E' wave (the average of the septal e' and lateral e' measurements), was defined as decreased $(<9 \mathrm{~cm} / \mathrm{s})$ or normal $(\geq 9 \mathrm{~cm} / \mathrm{s})$. E/e' the ratio of peak early LV filling (E-wave) and average tissue Doppler e' wave, was stratified into normal $(<8)$ and increased $(\geq 8)$. We defined DCT, the deceleration time of early filling velocity, into low $(<140 \mathrm{~ms})$, normal $(140-220 \mathrm{~ms})$ and high ( $>220 \mathrm{~ms})$. Isovolumetric relaxation time (IVRT) was reduced $(<60 \mathrm{~ms})$, normal $(60-110 \mathrm{~ms})$, or prolonged $(>110 \mathrm{~ms})$. The ratio of the transmittal early and late filling phases (E/A) was calculated as a measure of diastolic function. The ratio of early filling and early myocardial velocity $\left(\mathrm{E} / \mathrm{e}^{\prime}\right)$ was calculated as a noninvasive index of LV filling pressure.

Definition of diastolic dysfunction was as follows:

a. LAVI $>34 \mathrm{~mL} / \mathrm{m}^{2}$.

b. $\quad$ E/A $<0.8 ; \mathrm{e}^{\prime}<8 \mathrm{~cm} / \mathrm{s}$ \& mean $\mathrm{E} / \mathrm{e}^{\prime} \geq 8$ : impaired relaxation (DD) of grade I).

c. $\mathrm{E} / \mathrm{A} \leq 1.5 ; \mathrm{e}^{\prime}<8 \mathrm{~cm} / \mathrm{s}$ \& mean E/e' 9-12: pseudonormalized pattern (DD of grade II).

d. $\quad \mathrm{E} / \mathrm{A}>2 ; \mathrm{e}^{\prime}<8 \mathrm{~cm} / \mathrm{s}, \&$ mean $\mathrm{E} / \mathrm{e}^{\prime} \geq 13$ : restrictive patter $\mathrm{n}$ (DD of grade III).

e. Elevated LV filling pressure was defined as when E/E' ratio exceeded 14 .

Throughout all echocardiographic findings, a consensus reading was again applied.

\section{Statistical Analysis}

Baseline clinical characteristics and echocardiographic measures were summarized for participants with and without MetS. The collected data were entered in the software SPSS for Windows, version 19.0, which performed a statistical analysis. The distribution of variables was tested for normality using the Kolmogorov-Smirnov test, and the heterogeneity of variances was evaluated by Levene's test. A simple descriptive analysis was performed for the general characterization of the sample and distribution of variables. Continuous variables were presented as mean \pm standard deviation, and categorical variables were presented as frequency (\%). Differences between groups were analyzed using the Student t-test, for independent samples. Categorical data were analyzed using the Chi-square $\left(\mathrm{X}^{2}\right)$ test. The association between variables was analyzed using logistic regression. A, $p$ value $<0.05$ was considered statistically significant for a confidence interval of $95 \%$.

\section{Results}

A total of 550 subjects were enrolled in our study, including 450 subjects with MetS (mean age 50, 6 years, 49\% women), and 100 controls without MetS (mean age 50,1 years, 57\% women). Baseline characteristics by group are displayed in (Table 1). Overall subjects with MetS had a worse cardiovascular risk factor profile, including higher BMI, higher BP, elevated WC and dyslipidemia. $(25,5 \pm 3,2$ vs. $24,3 \pm 0,7 \mathrm{p}=0.01 ; 135,7 \pm 18,4$ vs. $118,7 \pm 2,2 \mathrm{p}=0,04 ; 87,9 \pm 10,5$ vs. $78,7 \pm 3,1 \mathrm{p}=0.006 ; 0,9 \pm 0,2$ vs. $1,2 \pm 0,6 p=0.00 ; 1,9 \pm 0,4$ vs. $1,4 \pm 0,1 p=0.04$ ). Fifty five percent (55\%) of subjects with MetS met at least three of the established criteria, while fourteen percent (14\%) of subjects with MetS met five of the established criteria.

Table 1: Basic demographic, anthropometric, laboratory and echocardiographic characteristics of study population.

\begin{tabular}{|c|c|c|c|c|c|c|c|c|}
\hline \multirow{2}{*}{\multicolumn{2}{|c|}{ Variables }} & \multicolumn{3}{|c|}{ Met.S (N.450) } & \multicolumn{3}{|c|}{ Controls (N.100) } & \multirow{3}{*}{$\begin{array}{c}\mathbf{p} \text {-value } \\
0.43\end{array}$} \\
\hline & & \multirow{2}{*}{$\begin{array}{c}\text { N.(\%) } \\
222(49,3)\end{array}$} & \multirow[t]{2}{*}{ Men } & \multirow[t]{2}{*}{ SD } & \multirow{2}{*}{$\begin{array}{c}\text { N.(\%) } \\
57(57 \%)\end{array}$} & \multirow[t]{2}{*}{ Mean } & \multirow[t]{2}{*}{ SD } & \\
\hline$S_{0}$ & Females & & & & & & & \\
\hline Genaer & Males & $228(50,7)$ & & & $43(43 \%)$ & & 0.41 & 0.43 \\
\hline \multicolumn{2}{|c|}{ Age (year) } & 50,6 & $\pm 3,9$ & & 50,1 & $\pm 3,7$ & 0.18 & \\
\hline \multicolumn{2}{|c|}{ BMI $\left(\mathrm{kg} / \mathrm{m}^{2}\right)$} & 25,5 & $\pm 3,2$ & & 24,3 & $\pm 0,7$ & $0.01^{*}$ & \\
\hline \multicolumn{2}{|c|}{ SBP (mmHg) } & 135,7 & $\pm 18,4$ & & 118,7 & $\pm 2,2$ & $0,04^{*}$ & \\
\hline \multicolumn{2}{|c|}{ DBP (mmHg) } & 87,9 & $\pm 10,5$ & & 78,7 & $\pm 3,1$ & $0.006^{*}$ & \\
\hline \multicolumn{2}{|c|}{ T2DM } & $324(72)$ & & & $0(0)$ & & & \\
\hline \multicolumn{2}{|c|}{ WCi(cm.) } & $381(84)$ & 97,5 & $\pm 8,7$ & $0(0)$ & 84,7 & $\pm 7,8$ & $0.00^{*}$ \\
\hline \multicolumn{2}{|c|}{ HDL-chlol(mmol/l) } & $303(67)$ & 0,9 & $\pm 0,2$ & & 1,2 & $\pm 0,6$ & $0.00^{*}$ \\
\hline \multicolumn{2}{|c|}{ Triglicer(mmol/l). } & $251(56)$ & 1,9 & $\pm 0,4$ & $0(0)$ & 1,4 & $\pm 0,1$ & $0.04^{*}$ \\
\hline \multicolumn{2}{|c|}{ CRP (mg/L) } & 4.9 & \pm 1.7 & & 1.6 & \pm 0.2 & $0.000^{*}$ & \\
\hline \multicolumn{2}{|c|}{ Three MetS riskfac. } & $248(55)$ & & & $0(0)$ & & & \\
\hline \multicolumn{2}{|c|}{ Four MetS risk fac. } & $139(31)$ & & & $0(0)$ & & & \\
\hline \multicolumn{2}{|c|}{ Five MetS risk fac. } & $63(14)$ & & & $0(0)$ & & & \\
\hline \multicolumn{2}{|c|}{ LAVI $\left(\mathrm{ml} / \mathrm{m}^{2}\right)>34$} & $179(39,7)$ & & & $0(0)$ & & & \\
\hline \multicolumn{2}{|c|}{$\mathrm{E}(\mathrm{cm} / \mathrm{s})}$. & 0,77 & $\pm 2,2$ & & 0,87 & $\pm 0,12$ & $0.00^{*}$ & \\
\hline
\end{tabular}




\section{Journal of Cardiology \& Cardiovascular Therapy}

\begin{tabular}{|c|c|c|c|c|c|c|c|}
\hline A(cm/s.) & 0,63 & $\pm 0,8$ & & 0,54 & $\pm 0,11$ & $0.00^{*}$ & 0.01 \\
\hline E/A ratio $<0.8$ & $179(39,7)$ & & & $6(6)$ & & & \\
\hline e, (cm/s) & 8,1 & $\pm 0,5$ & & 8,5 & $\pm 0,3$ & $0.01^{*}$ & 0.00 \\
\hline E/ e, ratio $\geq 8$ & $179(39,7)$ & & & $6(6)$ & & $0.00^{*}$ & 0.00 \\
\hline DT(m/s) $>200$ & $179(39,7)$ & 199,7 & $\pm 1,2$ & $6(6)$ & 183,3 & $\pm 20,14$ & $0.00^{*}$ \\
\hline IVRT(m/s) >100 & $179(39,7)$ & 101,9 & $\pm 22,1$ & $6(6)$ & 89,5 & $\pm 10,12$ & $0.00^{*}$ \\
\hline LVMI (gr/m $\left./ \mathrm{m}^{2}\right)$ & & 59,5 & $\pm 1,9$ & & 32,1 & $\pm 7,5$ & $0.00^{*}$ \\
\hline
\end{tabular}

Values are mean $\pm \mathrm{SD} ; \mathrm{y}=y e a r ; \mathrm{BMI}$ :body mass index;SBP:systolic blood presure;DBP:diastolic blod presure;T2DM:diabetes mellitus type 2 ; serumHDL-C-high.density cholesterol; serum Triglicerides; hs-CRP:high snsitive C-reative protein; WCi: increased weist circumference; LVVIlevt arial volum index; Mitral E:peak wave;: Mitral A peak wave; E/A ratio: early to late transmitral flow velosity; E/E'-ratio:early transmitral flow to average mitral tisue doppler; DT: deceleration time; IVRT-isovolumetric relaxation time; LVMI: left ventricular masindex. MetS: number of risk factor presnt (three,four,five).

Overall, subjects with MetS had a worse cardiovascular risk factor profile, including higher BMI, higher BP, increased WCi and dyslipidemia. $p^{*}<0.05$ for between group comparation.

Echocardiographic measures for control and MetS groups are presented in (Table 1). There were no differences in LV dimensions and LVEF between groups. Subjects with MetS have greater $\mathrm{LV}$ mass index $(59,5 \pm 1,9$ vs. $32,1 \pm 7,5 \mathrm{p}=0.00)$. Subjects with MetS also had worse measures of diastolic function, including: higher LAVI, lower E/A ratio and lower mean e', lower E/e' ratio, increased DCT and IVRT $(0,77 \pm 2,2$ vs. $0,87 \pm 0,12 \mathrm{p}=0.00 ; 0,63 \pm 0,8$ vs. $0,54 \pm 0,11 \mathrm{p}=0.00 ; 39,7 \%$ vs. $6 \% \mathrm{p}=0.00 ; 8,1 \pm 0,5$ vs. $8,5 \pm 0,3$ $\mathrm{p}=0.01 ; 39,7 \%$ vs. $6 \% \mathrm{p}=0.00 ; 39,7 \%$ vs. $6 \% \mathrm{p}=0.00 ; 39,7 \%$ vs. $6 \%$ $\mathrm{p}=0.00$ ). As shown in Table 2 and Figure 1, participants with MetS, have significantly increased frequency of subclinical LVDD grade 1 , in comparation with participants without MetS. (39,7\% vs. $6 \%$, $\mathrm{p}=0.0005$ ). The overall frequency of subclinical LVDD grade 1 , in participants with MetS, was 39,7\%; $\mathrm{p}=0.0005)$.

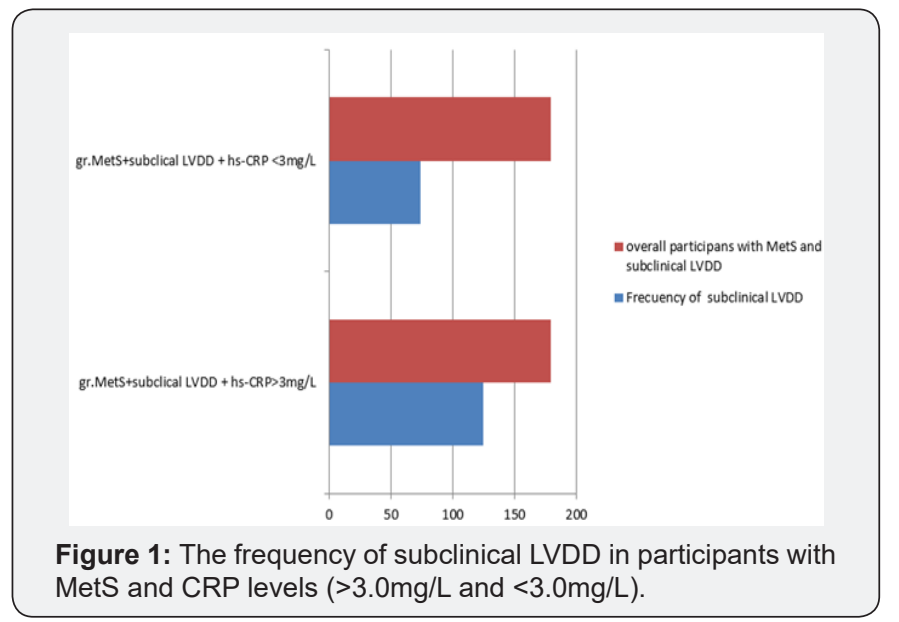

Table 2: Demographic, anthropometric and laboratory characteristics of group with subclinical LVDD (n-180) and group with normal LVDF (n-270) among patients with Met.S (n.450)

\begin{tabular}{|c|c|c|c|c|c|c|c|c|}
\hline \multirow{3}{*}{\multicolumn{2}{|c|}{ Variables }} & \multicolumn{6}{|c|}{ Gr. with Met.S (N.450) } & \multirow{3}{*}{$P$ - value } \\
\hline & & \multicolumn{3}{|c|}{ Gr. with subclinical LVDD (n-180) } & \multicolumn{3}{|c|}{ Gr.with normal LVDF (n.270) } & \\
\hline & & N. (\%) & Mean & $\pm \mathrm{SD}$ & N. (\%) & Mean & $\pm \mathrm{SD}$ & \\
\hline \multirow{2}{*}{ Gender } & Females & $122(68)$ & & & $100(37 \%)$ & & & $0.001^{*}$ \\
\hline & Males & $57(32)$ & & & $171(63 \%)$ & & & $0.004^{*}$ \\
\hline Age (year) & & & 51,5 & $\pm 3,5$ & & 50,1 & $\pm 3,8$ & 0.68 \\
\hline BMI $\left(\mathrm{kg} / \mathrm{m}^{2}\right)$ & & & 26,9 & $\pm 3,1$ & & 24,6 & $\pm 3,0$ & $0.001^{*}$ \\
\hline SBP (mmHg) & & $114(64)$ & 138,3 & $\pm 18,0$ & $201(74)$ & 134,0 & $\pm 18,5$ & $0,000^{*}$ \\
\hline DBP (mmHg) & & & 89,7 & $\pm 10,2$ & & 86,8 & $\pm 10,6$ & $0.003^{*}$ \\
\hline T2DMm & & $129(72)$ & & & $195(71)$ & & & 0.96 \\
\hline WCi $(\mathrm{cm})$. & & 149 (83) & 99,1 & $\pm 8,8$ & $232(85)$ & 94,9 & $\pm 8,0$ & $0.001^{*}$ \\
\hline HDL-chlol(mmol/l) & & $168(93)$ & 0,85 & $\pm 0,1$ & $135(49)$ & 1,0 & $\pm 0,2$ & $0.000^{*}$ \\
\hline $\mathrm{TG}(\mathrm{mmol} / \mathrm{l})$ & & $136(76)$ & 2,1 & $\pm 0,5$ & $115(42)$ & 1,7 & $\pm 0,4$ & $0.000^{*}$ \\
\hline CRP (mg/dL) & & & 6.6 & \pm 1.4 & & 3.7 & \pm 0.6 & $0.000^{*}$ \\
\hline Three MetS risk fac. & & $62(35)$ & & & $186(68)$ & & & $0.001^{*}$ \\
\hline Four MetS risk fac. & & $76(42)$ & & & $63(23)$ & & & $0.002^{*}$ \\
\hline Five MetS risk fac. & & $42(23)$ & & & $21(0,7)$ & & & $0.001 *$ \\
\hline
\end{tabular}

Values are mean \pm SD; y=year; BMI: body mass index; SBP: systolic blood presure; DBP:diastolic blod presure; T2DM: diabetes mellitus type 2; serum HDL-C-high.density cholesterol; serum Triglicerides; WCi: weist circumference; MetS.number of risk factor presnt (three,four,five). 
Overall, participants with subclinical LVDD, had a worse cardiovascular risk factor profile, including higher BMI, higher BP, increased WCi, dyslipidemia, high number of risk factors. $p^{*}<0.05$ for between group comparation.

Baseline demographic, anthropometric and laboratory characteristics of participants with MetS, stratified by presence of subclinic LVDD are displayed in Table 3. There was significant changes in relation to frequency of subclinic LVDD between females and males. Females have higher frequency of subclinical LVDD in comparison with males. (68\% vs.32\%; p=0.001). Participants with subclinical LVDD were older than participants with normal diastolic function $(\mathrm{p}=0.001)$. Overall, participants with subclinical
LVDD had a worse cardiovascular risk factor profile, including higher BMI, higher BP, elevated WC and dyslipidemia. (26,9 $\pm 3,1$ vs. $24,6 \pm 3,0 \mathrm{p}=0.001 ; 138,3 \pm 18,0$ vs. $134,0 \pm 18,5 \mathrm{p}=0,000 ; 89,7 \pm 10,2$ vs. $86,8 \pm 10,6 p=0.003 ; 99,1 \pm 8,8$ vs. $94,9 \pm 8,0 p=0.001 ; 0,85 \pm 0,1$ vs. $1,0 \pm 0,2 \mathrm{p}=0.000 ; 2,1 \pm 0,5$ vs. $1,7 \pm 0,4 \mathrm{p}=0.000$ ). Also, participants with subclinical LVDD, have higher number of risk factors for MetS than participants with normal diastolic function ( $42 \%$ vs. $23 \%$ $\mathrm{p}=0.002 ; 23 \%$ vs. $0,7 \% \mathrm{p}=0.001$ ).

Table 3: Frequency of subclinical LVDD among patients of the group with MetS and subclinical LVDD stratifyed by levels of CRP. ( $n-180)$.

\begin{tabular}{|c|c|c|c|}
\hline \multicolumn{3}{|c|}{ Chi-square: 10.91; $\mathbf{p}^{*}=\mathbf{0 . 0 0 1}$} \\
Study Group: MetS + subclinical LVDD (n-180) \\
\hline \multicolumn{2}{|c|}{ Participants with CRP > 3.0mg/L } & \multicolumn{2}{c|}{ Participants with CRP < 3.0mg/L } \\
\hline Frequency of subclinical LVDD & 117 & 63 & $\mathrm{p}^{*}=0.001$ \\
\hline Count (No) & 65 & 35 & \\
\hline Percent (\%) & & & \\
\hline
\end{tabular}

Overall, frequency of subclinical LVDD in Participants with MetS and levels of CRP >3.0mg/L was higher than in participants with MetS and levels of CRP $<3.0 \mathrm{mg} / \mathrm{L}$. $\mathrm{P}^{*}<0.05$ for between subgroup comparation.

Table 4: Echocardiographic characteristics of group with subclinic LVDD (n-179) and group with normal diastolic function (n-271) among patient with Met.S (n.450).

\begin{tabular}{|c|c|c|c|c|}
\hline & \multirow{2}{*}{ OR* } & \multirow{2}{*}{ Significance } & \multicolumn{2}{|c|}{$\mathbf{9 5 \%}$ CI for Exp (B) } \\
\cline { 3 - 5 } & & & Lower & Upper \\
\hline Subclinical LVDDf & 2.1 & .000 & 1.869 & 2.522 \\
\hline MetS-RF n4 & 1.4 & .000 & 1.485 & 1.950 \\
\hline MetS-RF n5 & 2.3 & .000 & 1.934 & 2.815 \\
\hline BMI & 1.5 & .000 & 1.380 & 1.730 \\
\hline T2DM & 1.2 & .000 & 1.048 & 1.349 \\
\hline
\end{tabular}

subclinic LVDD: Levt ventricular diastolic dysfunction; number of risk factor for MetS, $n$-four: four risk factors for MetS; $n$-five: five risk factors for MetS; DM: Diabetes Mellitus and BMI: Body mass index. OR* $>1$.

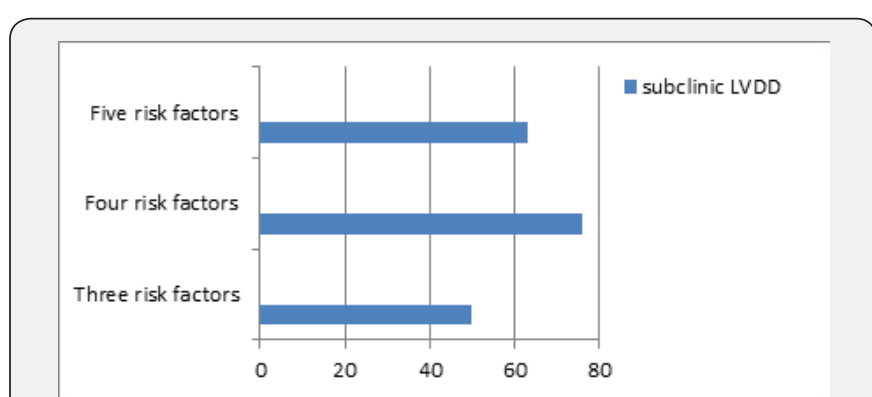

Figure 2: Frequency of subclinic LVDD among patient with different number of risk factors among patient with Met.S (n.450).

Echocardiographic measures for group with subclinical LVDD and group with normal diastolic function among participants with MetS, are presented in Table 4 and Figure 2. Participants with subclinical LVDD had worse measures of diastolic function, Including: higher LAVI, lower Mitral E peak wave, higher Mitral A peak wave, lower E/A ration, lower mean e,; E/e, ratio $\geq 8$, increased DT $(\mathrm{m} / \mathrm{s})>200$; increased IVRT $(\mathrm{m} / \mathrm{s})>100 .(0,53 \pm 0,1$ vs. $0,76 \pm 0,1 \mathrm{p}=0.00 ; 0,81 \pm 0,13$ vs. $0,51 \pm 0,8 \mathrm{p}=0.00 ; 39,7 \%$ vs. $6 \%$ $\mathrm{p}=0.00 ; 8,1 \pm 0,5$ vs. $8,5 \pm 0,3 \mathrm{p}=0.01 ; 39,7 \%$ vs. $6 \% ; \mathrm{p}=0.00 ; 39,7 \%$ vs $6 \% p=0.000 ; 218,5 \pm 24,1$ vs. $187,4 \pm 16,9 p=0.00 ; 39,7 \%$ vs. $6 \%$ $\mathrm{p}=0.000 ; 124,9 \pm 15,6$ vs. $86,7 \pm 8,38 \mathrm{p}=0.00$ ).

Association of subclinical LVDD with: demographic, anthropometric and clinical parameters are displayed in Table 5. There is a significantassociation between subclinical LVDD and ages in patient with MetS (OR=1.108, 95\%CI 1.051-1.168). There was observed significant association between subclinical (LVDD) and females among patient with MetS. Females, for (OR=3.63;95\%CI 2.439-5.413) have 1.29 times higher risk for sub-clinic LVDD in comparation with males. Significant association between subclinical LVDD and BMI were observed among participants with MetS. Participants with increased BMI, for (OR=7.474; 95\% CI 4.881-11.443) have 2.011 times higher risk for subclinical LVDD in comparation to participants with normal BMI. Uncontrolled BP in patient with MetS was significantly associated with subclinical LVDD. Participants with subclinical LVDD, for (OR=1.763; 95\%CI 1.204-2.580) have 0.56 times higher risk for subclinical LVDD in comparation to participants with controlled BP. The number of risk factors for MetS also was associated with subclinical LVDD. For (OR=3.609; 95\%CI 2.054-6.340) participants with five RF have 1.28 times higher risk for subclinical LVDD in comparation to participants with three RF. 
Table 5: Logistic regression model: association of sub-clinic LVDD and; Ages, BMI, Cont.BP and MetS-RF number, in patient with MetS.

\begin{tabular}{|c|c|c|c|c|c|c|c|c|c|}
\hline & & B & S.E. & Wald & df & Sig. & $\operatorname{Exp}(B)$ & \multicolumn{2}{|c|}{ 95\% C.I.for EXP(B) } \\
\hline & & & & & & & & Lower & Upper \\
\hline \multirow{2}{*}{ Step $1^{\mathrm{a}}$} & AGES & 0.102 & 0.027 & 14.514 & 1 & 0 & 1.108 & \multirow{2}{*}{1.051} & \multirow{2}{*}{1.168} \\
\hline & Constant & -5.602 & 1.372 & 16.683 & 1 & 0 & 0.004 & & \\
\hline \multirow{2}{*}{ Step $1^{\mathrm{a}}$} & Females & 1.29 & 0.203 & 40.216 & 1 & 0 & 3.633 & \multirow{2}{*}{2.439} & \multirow{2}{*}{5.413} \\
\hline & Constant & -1.081 & 0.152 & 50.631 & 1 & 0 & 0.339 & & \\
\hline \multirow{2}{*}{ Step $1^{\mathrm{a}}$} & Cat.BMI & 2.011 & 0.217 & 85.643 & 1 & 0 & 7.474 & \multirow{2}{*}{4.881} & \multirow{2}{*}{11.443} \\
\hline & Constant & -1.267 & 0.146 & 75.142 & 1 & 0 & 0.282 & & \\
\hline \multirow{2}{*}{ Step $1^{\mathrm{a}}$} & Contr.BP & 0.567 & 0.194 & 8.504 & 1 & 0.004 & 1.763 & \multirow{2}{*}{1.204} & \multirow{2}{*}{2.58} \\
\hline & Constant & -0.687 & 0.139 & 24.469 & 1 & 0 & 0.503 & & \\
\hline \multirow{2}{*}{ Step $1^{\text {a }}$} & MetS-RF n-.five. & 1.283 & 0.288 & 19.917 & 1 & 0 & 3.609 & \multirow{2}{*}{2.054} & \multirow{2}{*}{6.34} \\
\hline & Constant & -0.59 & 0.106 & 30.929 & 1 & 0 & 0.554 & & \\
\hline
\end{tabular}

BMI: Body Mas Index; Cont.BP: control of Blood Presure; Mets-RF n: number of Risk Factor present (n-five).

\section{Discussion}

In this study, we observed that the frequency of subclinical LVDD among patient with MetS was significantly increased in comparation to patient without MetS. $(39,7 \%$ vs. $6 \%$; $=0.0005$, respectively). We found that MetS was associated with subclinical LV diastolic dysfunction as reflected by higher: LAVI, lower E/A ratio, increased E/e, ratio, prolonged DCT and prolonged IVRT, in a sample of individuals without existing cardiovascular disease. These findings suggest that MetS can lead to the development of diastolic dysfunction via mechanisms that are independent of hypertrophy, coronary disease, and potentially lead further insights into the increased cardiovascular risk observed in MetS [19-21].

The influence of gender in the prevalence of LVDD is proved in some but not in all reports [22]. In our study was observed significant gender difference in frequency of subclinical LVDD among participants with MetS. Females have higher frequency of subclinical LVDD than males. These data are in line with earlier observations [23]. Attention to gender specifies should be a mandatory pre-requisite of clinical and epidemiological research on MetS and cardio-vascular disease, for better knowledge and development of health strategies.

In the present study, in group of MetS, subclinical LVDD was significantly associated with age. A number of previous studies have demonstrated that frequency of subclinical LVDD among patient with MetS significantly increased increasing the age [24]. As the reduced ventricular compliance is secondary to the ageing process, since the ventricular stiffness increases with age and impairs diastolic function altering LV filling pressure. Nevertheless, nature of the some Doppler-echocadiographic changes with aging is partially unclear and precise discrimination between pathologic or physiologic changes remains difficult. Our results are consistent with prior studies showing an association of MetS and increased in LV mass [25]. While elevated BP is one of the important components of MetS, and hypertension is known to lead to increases in LV mass [26]. Previous study, not at all, reported situation of increased in LV mass and elevated BP, whereas Nir Avalon et al. [27] in their study, founded that the association of MetS and increased LV mass, was independent of blood pressure.

In the present study, BMI, SBP, DBP and triglycerides were significantly higher in the MetS patients with subclinical LVDD than in the MetS patients without subclinical LVDD, whereas lower high-density lipoprotein cholesterol were significantly decreased in the metabolic syndrome patients with subclinical LVDD than in the metabolic syndrome patients without subclinical LVDD. Our results are consistent with prior studies [27-29]. A cluster of these cardiovascular risk factors may produce latent cardiac diastolic dysfunction in metabolic syndrome.

Left ventricular diastolic function (LVDF) appears to worsen in a stepwise fashion with the number of risk factors for MetS. In the present study number of risk factors were significantly higher in the metabolic syndrome patients with subclinical LVDD than in the metabolic syndrome patients without subclinical LVDD, Our results are consistent with prior studies [4,7].

The pathophysiological mechanism by which MetS can lead to abnormalities in LV diastolic function is not well understood. In mouse models of diet-induced MetS, increased myocardial oxidative stress has been implicated in the development of diastolic dysfunction, and was associated with both hypertrophy and fibrosis of the myocardium [30]. Animal models of insulin resistance, hypertension, or dyslipidemia have also implicated the development of cardiac fibrosis, abnormal intracellular calcium handling [30,31], cardiomyocyte, lipotoxicity, mitochondrial dysfunction, impaired endothelial blood flow, increased vascular stiffness, and inflammation [32]. While mechanistic inferences cannot be drawn from our observational study, these results support the notion that metabolic heart disease can lead to impaired myocardial relaxation in the absence of. Further studies are needed to elucidate potential mechanisms and potential therapeutic targets. 
Several limitations deserve mention. Our study is a crosssectional observational study, and causal inferences are therefore limited. A larger sample would certainly increase the statistical power of the study and probably same differences would therefore become more expressive. Healthy controls were selected based on the absence of any MetS criteria. This resulted by design in baseline differences of clinical characteristics between participants with and without MetS. It is therefore possible that residual confounding could in part account for our findings. It was impossible to rule out coronary heart disease as a reason for subclinical LVDD by coronary angiography, because it is difficult to influence asymptomatic patients for an invasive procedure and also from ethical standpoint. This limitation is unavoidable. We do not believe that subtle coronary atherosclerosis would have an influence in the study results at a significant degree, and will not reduce the values of the basic conclusions of the study as well.

\section{Conclusion}

The prevalence of subclinical LVDD in the patients with MetS, in absence of coronary heart disease and other well know heart disease, is considerably high, in western region of the Republic of Macedonia and seems to be significantly associated with age, gender, BMI, LVM and high number of risk factors for MetS. Attention to high prevalence of subclinical LVDD in the patients with MetS, should be a mandatory pre-requisite of clinical and epidemiological research on MetS and cardio-vascular disease, for better knowledge and development of health strategies for primary prevention of manifested heart failure.

\section{Authorship Contributions}

a) Concept: Ylber Jani, Design-Bekim Pocesta

b) Supervision: Atila Rexhepi

c) Materials: Fatmir Ferati, Dali Lala, Agim Zeqiri, Arben Mirto

d) Data collection/processing: Sotiraq Xhunga, Artur Serani

e) Analysis/interpretation: Ylber Jani, Atila Rexhepi, Bekim Pocesta

f) Literature search: Dali Lala, Fatmir Ferati, Ylber Jani, Artur Serani

g) Critical reviews: Ahmet Kamberi, Atila Rxhepi

\section{Acknowledgment}

We thank Ahmet Kamberi PhD, Atila Rexhepi PhD, Dali Lala MD, Fatmir Ferati PhD, Agim Zeqiri MD, Arben Mirto MD, for their contributions to this study.

\section{References}

1. Reaven GM (1988) Role of insulin resitance in human disease. Diabetes 37(12): 1595-1607.

2. Qiao Q (2006) The DECODE Study Group. Comparation of different definition on the metabolic syndrome in relation to cardiovascular mortality in european men and women. Diabetologia 49(12): 28372846.

3. McNeill AM, Rosamond WD, Girman CJ, Golden SH, Schmidt MI, et al. (2005) The metabolic syndrome and 11-year risk of incident cardiovascular disease in the atherosclerosis risk in communities study of diabetes. Diabetes Care 28(2): 385-390.

4. De las Fuentes L, Brown AL, Mathews SJ, Waggoner AD, Soto PF, et al. (2007) Metabolic syndrome is associated with abnormal left ventricular diastolic function independent of left ventricular mass. Eur Heart J 28(5): 553-559.

5. Bella JN, Palmieri V, Roman MJ, Liu JE, Welty TK, et al. (2002) Mitral ratio of peak early to late diastolic filling velocity as a predictor of mortality in middle-aged and elderly adults: the Strong Heart Study. Circulation 105(16): 1928-1933.

6. Kane GC, Karon BL, Mahoney DW, Redfield MM, Roger VL, et al. (2011) Progression of left ventricular diastolic dysfunction and risk of heart failure. JAMA 306(8): 856-863.

7. Azevedo A, Bettencourt P, Almeida PB, Santos AC, Abreu-Lima C, et al. (2007) Increasing number of components of the metabolic syndrome and cardiac structural and functional abnormalities--cross-sectional study of the general population. BMC Cardiovasc Disord 7: 17.

8. Ford ES (2005) Risks for all-cause mortality, cardiovascular disease, and diabetes associated with the metabolic syndrome: a summary of the evidence. Diabetes Care 28(7): 1769-1778.

9. Levesque J, Lamarche B (2008) The metabolic syndrome: definitions, prevalence and management. J Nutrigenet Nutrigenomics 1(3): 100108.

10. Alberti KG, Eckel RH, Grundy SM, Zimmet PZ, Cleeman JI, et al. (2009) International Diabetes Federation Task Force on Epidemiology and Prevention, and Hational Heart, Lung, and Blood Institute. Harmonizing the metabolic syndrome: a joint interim statement of the International Diabetes Federation Task Force on Epidemiology and Prevention; National Heart, Lung, and Blood Institute; American Heart Association; World Heart Federation; International Atherosclerosis Society; and International Association for he Study of Obesity. Circulation 120(16): 1640-1645.

11. Chobanian AV, Bakris GL, Black HR, Cushman WC, Green LA, et al. (2003) The seventh report of join National Committee on Prevention, Detection, Evaluation and treatment of high blood pressure: the JNC 7 report. JAMA 289(19): 2550-2572.

12. America Diabetes Association (2002) Standards for medical care for patient with diabetes mellitus. Diabetes Care 26(Suppl 1): S33-S50.

13. Nagueh SF, Appleton CP, Gillebert TC, Marino PN, Oh JK, et al. (2009) Recommendations for the evaluation of left ventricular diastolic function by echocardiography. J Am Soc Echocardiogr 22(2): 107-133.

14. Dewereux RB, Alonso DR, Lutas EM, Gottlieb GJ, Campo E, et al. (1986) Ehocardiografic of left ventricular hypertrophy: comparation to necropsy findings. Am J Cardiol 57(6): 450-458.

15. De Simone G, Daniel RS, Devereux RB, Meyer RA, Roman MJ, et al. (1992) Left ventricular mass and body size in normotensive children and adults: assessment of allometric relations and impact of overweight. J Am Coll Cardiol 20(5): 1251-1260.

16. Nagueh SF, Appleton CP, Gillebert TC, Marino PN, Oh JK, et al. (2009) Recommendations for the evaluation of left ventricular diastolic function by echocardiography. Eur J Echocardiogr 10(2): 165-193.

17. Lang RM, Badano LP, Mor-Avi V, Afilalo J, Armstrong A, et al. (2015) Recommendations for cardiac chamber quantification by echocardiography in adults: an update from the American society of echocardiography and the European association of cardiovascular imaging. Eur Heart J Cardiovasc Imaging 16(3): 233-271. 
18. Nagueh SF, Smiseth OA, Appleton CP, Byrd BF, Dokainish H, et al. (2016) Recommendations for the evaluation of left ventricular diastolic function by echocardiography: an update from the American Society of Echocardiography and the European Association of Cardiovascular Imaging. J Am Soc Echocardiogr 29(4): 277-314.

19. Ford ES (2005) Risks for all-cause mortality, cardiovascular disease, and diabetes associated with the metabolic syndrome: a summary of the evidence. Diabetes Care 28(7): 1769-1778.

20. Gami AS, Witt BJ, Howard DE, Erwin PJ, Gami LA, et al. (2007) Metabolic syndrome and risk of incident cardiovascular events and death: a systematic review and meta-analysis of longitudinal studies. J Am Coll Cardiol 49(4): 403-414.

21. Yung ME, Mc Nultry P, Taegtmeyer H (2002) Adaptation and maladaption of the heart in diabetes: Part II: potential mechanisms. Circulation 105(15): 1861-1870.

22. Fang ZY, Schull-Meade R, Downey M, Prins J, Marwich TH (2005) Determinants of subclinical diabetic heart disease. Diabetologia 48(2): 34-402.

23. Jorgensen PG, Jensen MT, Biering-Sorensen T, Mogelvang R, Galatius $S$, et al. (2016) Cholesterol remnants and triglycerides are associated with decreased myocardial fungtion in patients with type 2 diabetes. Cardiovasc Diabetol 15(1): 137.

24. Dalen BM, Soliren OI, Kauer F, Vletter VB, Zwean HB, et al. (2010) ML alterations in left ventricular untwisting with ageing. Circ J 74(1): 101108.

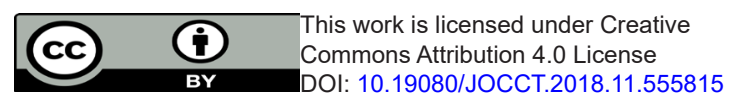

25. Burchfiel CM, Skelton TN, Andrew ME, Garrison RJ, Arnett DK, et al. (2005) Metabolic syndrome and echocardiographic left ventricular mass in blacks: the Atherosclerosis Risk in Communities (ARIC) Study. Circulation 112(6): 819-827.

26. Lorell BH, Carabello BA (2000) Left ventricular hypertrophy: pathogenesis, detection, and prognosis. Circulation 102(4): 470-479.

27. Nir A, Gopal DM, Mooney MD, Simonetti JS, Grossman JR, et al. (2014) Preclinical left ventricular diastolic dysfunction in metabolic syndrome. Am J Cardiol 114(6): 838-842.

28. Masugata H, Senda S, Goda F, Yoshihara Y, Yoshikawa K, et al. (2006) Left ventricular diastolic dysfunction as assessed by echocardiography in metabolic syndrome. Hypertens Res 29(11): 897-903.

29. Horio T, Miyazato J, Kamide K, Takiuchi S, Kawano Y (2003) Influence of low high-density lipoprotein cholesterol on left ventricular hypertrophy and diastolic function in essential hypertension. Am J Hypertens 16(11 Pt 1): 938-944.

30. Kuster GM, Lancel S, Zhang J, Communal C, Trucillo MP, et al. (2010) Redox-mediated reciprocal regulation of SERCA and $\mathrm{Na}+\mathrm{-Ca} 2+$ exchanger contributes to sarcoplasmic reticulum $\mathrm{Ca} 2+$ depletion in cardiac myocytes. Free Radic Biol Med 48(9): 1182-1187.

31. Morgan JP (1991) Abnormal intracellular modulation of calcium as a major cause of cardiac contractile dysfunction. N Engl J Med 325(9): 625-632.

32. Katz AM, Zile MR (2006) New molecular mechanism in diastolic heart failure. Circulation 113(16): 1922-1925.

\section{Your next submission with Juniper Publishers will reach you the below assets}

- Quality Editorial service

- Swift Peer Review

- Reprints availability

- E-prints Service

- Manuscript Podcast for convenient understanding

- Global attainment for your research

- Manuscript accessibility in different formats

( Pdf, E-pub, Full Text, Audio)

- Unceasing customer service

Track the below URL for one-step submission https://juniperpublishers.com/online-submission.php 